\title{
New applications of hydroacoustic methods for monitoring shallow water aquatic ecosystems: the case of mussel culture grounds
}

\author{
Patrice Brehmer ${ }^{\mathrm{a}, *}$, François Gerlotto ${ }^{\mathrm{b}}$, Jean Guillard ${ }^{\mathrm{a}, 1}$, Fabien Sanguinède ${ }^{\mathrm{a}}$, \\ Yvon Guénnegan ${ }^{\mathrm{c}}$, Dominique Buestel ${ }^{\mathrm{d}}$ \\ a Institut de Recherches pour le Développement, CRHMT/UR061 and USO04, BP 171, 34203 Sète, France \\ ${ }^{b}$ Institut de Recherches pour le Développement, Casilla 53390 Correo Central, Santiago-1, Chile \\ ${ }^{c}$ Institut français de recherche pour l'exploitation de la mer, CRHMT/RH, BP 171, 34203 Sète, France \\ ${ }^{d}$ Institut français de recherche pour l'exploitation de la mer COP, BP 7004, 98719 Taravao, Tahiti, French Polynesia
}

Accepted 7 March 2003

\begin{abstract}
The development of acoustics tools and methods for monitoring anthropized ecosystems represents a new field for the application of acoustics. Monitoring such an environment was not possible with single vertical echo sounders, due to the fact that the artificial structures and the natural targets were not distinguishable. Monitoring data were collected along the French Mediterranean coastline, during five short surveys of mussel culture longline areas. Both the Reson Seabat 6012 multibeam sonar (455 kHz) and the Simrad SR 240 omnidirectional sonar $(23.75 \mathrm{kHz})$ were used for target detection. The former tools allow accurate allocation of the different types of echoes to artefacts, fish schools and scattered fish. The school characteristics collected included morphological, geographical (GPS, school location), and behavioural (connections with the longlines). An acoustic survey undertaken with the same hardware near the study area allowed the comparison of fish schools and the TS distribution of individual fish in the open sea and in the mussel area. These data permitted us to evaluate the ecological impact of a mussel culture on the ecosystem, in a context of predation behaviour of fish on these longlines. Finally, the acoustic data revealed the configuration of each concession and the level of charge of each line. We discuss the applicability of this technology for in situ real time monitoring for joint management of such ecosystems. The information can allow littoral cooperative management or incorporating it into an ecosystem approach.
\end{abstract}

(C) 2003 Éditions scientifiques et médicales Elsevier SAS and Ifremer/IRD/Inra/Cemagref. All rights reserved.

Keywords: Multibeam sonar; Monitoring; Fish school; Mussel longline; Artificial reef; Ecosystem

\section{Introduction}

The conflicts engendered by the multiple uses of coastal ecosystems (fisheries, tourism, aquaculture, etc.) are becoming a major challenge for the environmental friendly development and exploitation of these areas. Since 1988, the development and management of several artificial reefs (Lacroix et al., 2002) and mussel culture fields in open sea along the French Mediterranean coastline have become a major economical activity (Loste and Cazin, 1993). First experimented in 1976 near Sète (the most important fisheries harbour along the French Mediterranean coastline), these devel-

\footnotetext{
* Corresponding author.

E-mail address: brehmer@ird.fr (P. Brehmer).

${ }^{1}$ Institut National de Recherche Agronomique, CARRTEL, BP 511, 74203, Thonon les Bains, France.
}

opments have induced several changes in the ecosystem. In 1996, new and heavy predation on mussels by Sparids was reported illustrating the need for exploited anthropized ecosystems to be monitored. Currently, acoustic observations are usually the only applicable monitoring method, as the area is too wide and turbid for routine visual observations and fishing gears cannot be deployed because of the great number of the artefacts present in the area. However, in such anthropized ecosystems, a scientific echo sounder alone may not permit the definition of specific targets because of these submerged artefacts Fig. 1. In the mussel aquaculture ground (MG), the echoes of longline structures cannot be distinguished from the echoes of fish and schools Fig. 2. This paper wants to demonstrate how the adaptation of acoustic methods with multibeam sonar makes it possible to monitor such a complex environment. Some illustrative preliminary results are presented. 

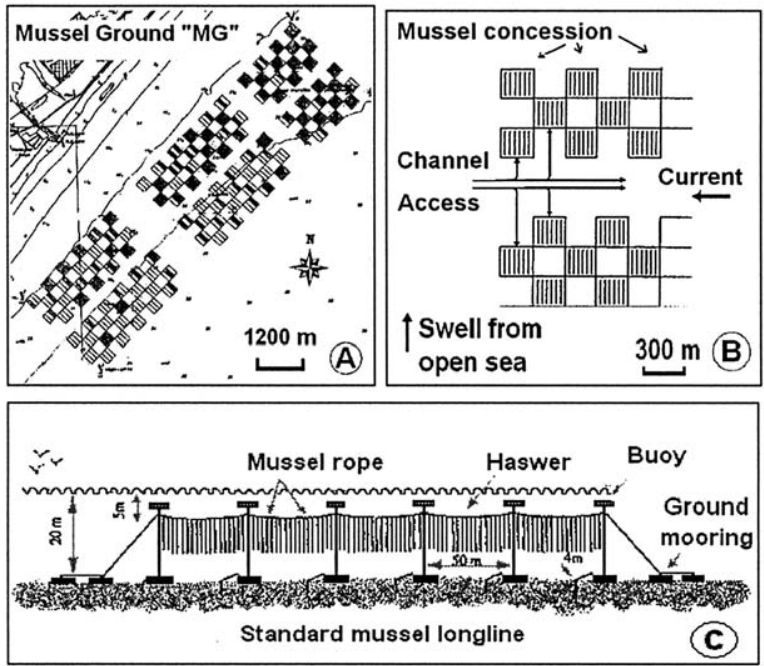

Fig. 1. Structure of the mussel ground, in open sea; channel access; the mussel production area (a) constituted by two longlines each; channel access (b) the mussel longlines are fixed by ground mooring and hung with buoy (c), the mussel ropes are hooked on the hawser, the main horizontal rope (after Lost and Cazin, 1993).

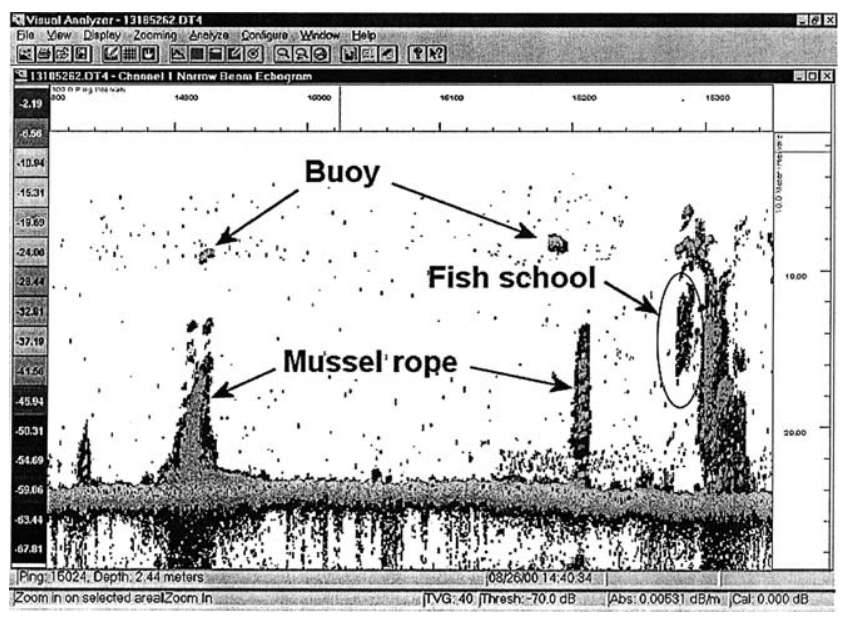

Fig. 2. A vertical echogram obtained with a Biosonics DT 5000 in the mussel ground (MG). It is impossible to discriminate the fish school (circled) from the mussel longline structure on the vertical echosounder (VES) records without information delivered by the multibeam side scan sonar (MBS).

\section{Materials and methods}

\subsection{Acoustic devices and mussel culture grounds}

Data were collected from five surveys during the summer of 2000 and 2001 using small boats adapted to manoeuvre inside the aquaculture field. In 2001, a set of observations were recorded aboard the $30 \mathrm{~m} \mathrm{R} / \mathrm{V}$ "l'Europe" out and near the MG using a portable echo sounder (VES) (either Simrad EY500 or Biosonics DT 5000, previously calibrated (Foote, 1987)) and a mutibeam side scan sonar Reson Seabat 6012 (MBS) Table 1). The latter was set on a vertical plane perpendicular to the vessel route, with the main axis either vertical (i.e. observing from $45^{\circ}$ port to $45^{\circ}$ starboard below the boat) or lateral (directed $45^{\circ}$, observing from $0^{\circ}$ to $90^{\circ}$ below the boat). Aboard the R/V "l'Europe", a long-range multibeam omnidirectional sonar (LOS) was employed following the methodology developed by Brehmer and Gerlotto (2000) to test the applicability of such tools in shallow waters. The total MG area, prohibited to navigation, covers 2754 ha Fig. 1a. Each concession (3 ha each) contained two mussel longlines of $250 \mathrm{~m}$ length, usually at $5 \mathrm{~m}$ depth from the surface and, between 20 and $30 \mathrm{~m}$ deep Fig. 1c. The longline structure was standard, where the hawser (main rope) was suspended horizontally by buoys and fixed to the bottom by secondary ropes each $50 \mathrm{~m}$, hooked by ground mooring concrete blocks Fig. 1c. The mussel ropes were hung vertically below the hawser.

\subsection{Sampling methods}

Morphometric and spatial data were collected on a total of 191 fish schools (140 inside the mussel area and 51 outside) with the MBS. A total of 7457 target strength (TS) values were processed on scattered fish using the VES: 1455 TS values outside the MG (night); 3467 inside (night); 605 inside (night with artificial light); 1527 inside (day).

The MBS and VES data were recorded simultaneously. The MBS video images allow clear discrimination of fish and artefact echoes Fig. 3. Once the discrimination has been completed, the corresponding vertical echogram can be easily cleaned Fig. 2). Then the biological target analysis, from VES and digital MBS, is performed and the main school parameters are measured (Gerlotto et al., 1999, 2001). The MBS images from the longline structure allow for threedimensional reconstruction. Two sets of images were collected, those obtained with the vessel crossing the longline and those with the vessel parallel to the longline Fig. 3. Three levels of mussel abundance on the mussel ropes were defined according to the MBS imagery: full, medium (in growth), and empty.

The same measurements on schools and scattered fish were performed outside the MG area (5 nautical miles far from the MG on the same isobaths) with the same acoustic devices and boat. No artificial reef and structure were encountered in this area. In the 2000 survey (IRD, Ifremer, SRCM) "lamparo" experiments (lighting $500 \mathrm{~W}$ ) $2 \mathrm{~m}$ above the sea surface (Nédélec and Prado, 1990) were conducted during which TS values were collected.

\section{Results}

The fish, school and mussel long line can be discriminated separately by acoustic methods. The results displayed here are methodological, and give some information on the kind of information a multibeam sonar can provide in such anthropized ecosystems, by the way of some examples. The three most important points that concern the observation are description of fish schools, the analysis of individuals (and specially fish TS), and the representation of the artificial structures such as the mussel longline present in the area. 
Table 1

Main characteristics and settings of the acoustic devices: the multibeam sonar (MBS), the vertical echosounder (VES) and the long-range multibeam omnidirectional sonar (LOS) used during the surveys 2000 and 2001

\begin{tabular}{|c|c|c|c|c|}
\hline Type & Reson Seabat 6012 & Biosonics DT5000 & Simrad EY500 & Simrad SR 240 \\
\hline Acronym & MBS & VES & VES & LOS \\
\hline Surveys & 07/2000;04-05/2001* & $07 / 2000$ & 07/2001;04-05/2001 & $10 / 2001$ \\
\hline Periods & Day/night (day)* & Day/night & Day/night & Day \\
\hline Frequency (kHz) & 455 & 129 & 70 & 23.75 \\
\hline Nb. beams & 60 & 1 dual beam & 1 split beam & 32 \\
\hline Beam shape & $1.5^{\circ} \times 22^{\circ}$ & $11^{\circ} \times 11^{\circ}$ & $11^{\circ} \times 11^{\circ}$ & $11.5^{\circ} \times 11.25^{\circ}$ \\
\hline TVG & $20 \log R$ & $40 \log R$ & 20 and $40 \log R$ & $30 \log R$ \\
\hline Power & $7-8$ & - & - & Full \\
\hline Gain & $4-5$ & - & - & 9 \\
\hline Ping rate & $7 / \mathrm{s}$ & Auto & Auto & Auto \\
\hline Pulse duration (ms) & 0.06 & 0.4 & 0.3 & 8 \\
\hline Range (m) & $50(50 / 100)^{*}$ & Auto & Auto & 800 \\
\hline Beam position & Vertical $\left(45^{\circ}\right)^{*}$ & Vertical & Vertical & Tilt $-2^{\circ}$ to $-5^{\circ}$ \\
\hline Sound celerity $\left(\mathrm{m} \mathrm{s}^{-1}\right)$ & 1500 & 1485 & 1505 & - \\
\hline Recording & Video + digital (video)* & Digital & Digital & Digital \\
\hline Zoom & 1 & - & - & - \\
\hline Scale & Linear & - & - & - \\
\hline Smoothing & Off & - & - & On \\
\hline Software & Sbiviewer 5.01 & DT analyser & Movies+ $3.3 a$ & Infobancs 3.0 \\
\hline
\end{tabular}

* During surveys in 2002
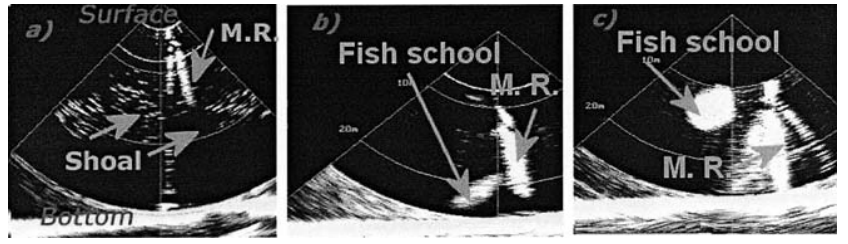

Fig. 3. Multibeam sonar display in lateral view (vertical transducer). Shoal around the mussel rope (a), 30 m-deep from surface (top) to bottom; fish schools near a mussel rope, M.R (b and c).

\subsection{Fish schools}

No school was detected during night surveys. The 191 schools recorded (Fig. 5) were on average $6.9 \mathrm{~m}$ in width, $3.4 \mathrm{~m}$ in height and $13.7 \mathrm{~m}$ in length (the maximal value was $120 \mathrm{~m}$ recorded outside the MG). The average distance from the bottom (altitude) was $5.1 \mathrm{~m}$ and their distance from the boat was $26.5 \mathrm{~m}$ (the minimum distance recorded was $2 \mathrm{~m}$ and occurred outside the $\mathrm{MG}$ ). When the schools were observed simultaneously with a longline ( $n=79$; Fig. 3), their average distance to the structure was $15.3 \mathrm{~m}$. Two phenomena that let us suspect that the schools could be attracted by the structure are: (i) no or very few schools were recorded in the access channel during the surveys, and (ii) due to the limited range and the directivity of the sonar beam, it was not always possible to record, on a single frame, the schools and the structure. Therefore, most of the 191 observed schools were actually close to the longline (unlike the limited number of 79 recordings with school and longline may suggest). The vertical distribution of fish schools was predominantly close to the bottom (0-8 $\mathrm{m}$ altitude) but inside the MG the fish school was detected in the whole water column (Brehmer, 2001), except during rough weather (above $5 \mathrm{~m}$ or below $18 \mathrm{~m}$ ). Horizontally, the fish schools were distributed over all the MG with a low density in the access channel except that they were more abundant on the open seaside of the MG during rough weather. The fish school characteristics were highly variable inside the $\mathrm{MG}$ (standard deviation: length, $6.7 \mathrm{~m}$; height, $2.0 \mathrm{~m}$; width, $3.4 \mathrm{~m}$ and altitude $4.3 \mathrm{~m}$ ) and varied according to the time of the day (Brehmer, 2001). The biggest schools were recorded at midday (from $1 \frac{1}{2} \mathrm{~h}$ before to $1 \frac{1 / 2}{\mathrm{~h}}$ after the zenith) and close to the bottom. The fish school morphometrics and position inside and outside the MG were significantly different (MANOVA, $P<0.05$ ) (Fig. 5); that is, schools were smaller, shallower and farther from the boat (avoidance)

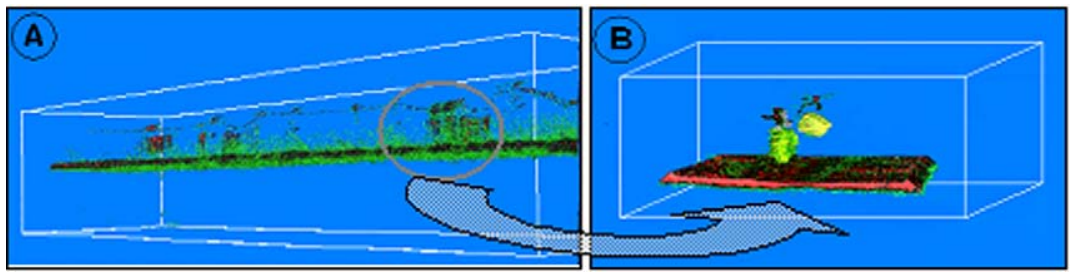

Fig. 4. Three-dimensional view of a mussel long line (a) and an enlargement of a fish school (b: zoom) from multibeam side scan sonar (MBS) processed data. The software allows identifying and measuring separately all the individual structures; b: the fish school (in yellow), the mussel rope (in green), the hawser and buoy (in grey), bottom (in red). 


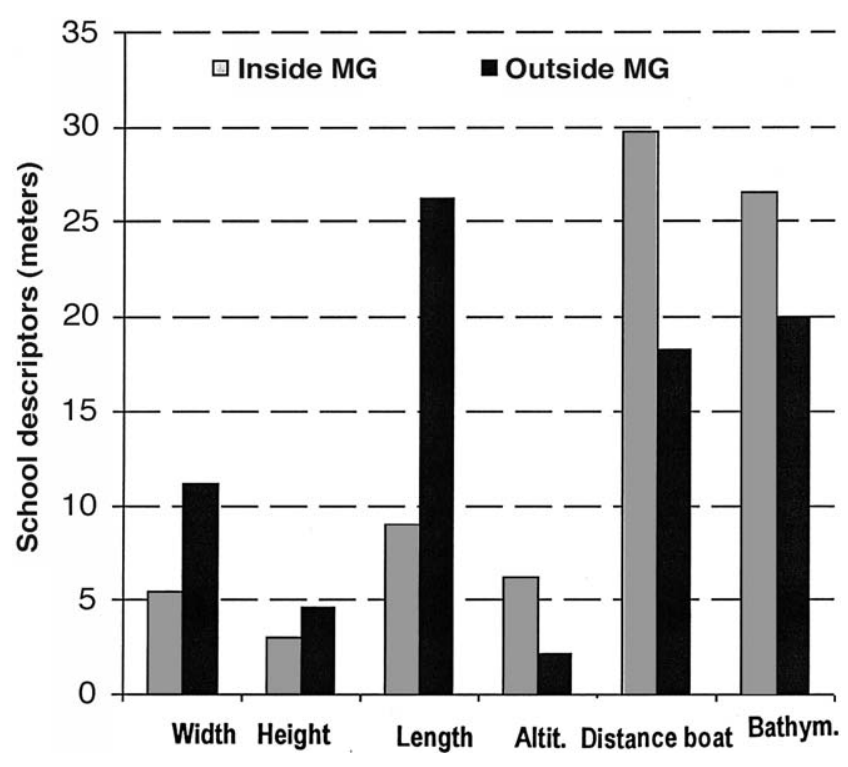

Fig. 5. Comparison of the fish school sonar descriptors, obtained inside and outside the mussel culture ground.

inside the MG. There were no significant correlations between the fish school descriptors (correlation matrix, $P<0.05$ ).

Fish school abundance, calculated as number per kilometre of transect, was higher inside the MG (2.3 school km$\left.{ }^{-1}\right)$ than outside $\left(1.9\right.$ school km $\mathrm{km}^{-1}$ ), but the volume (length $\times$ width $\times$ height) was six times higher outside the MG. Limited visual observations by divers (inside, summer 2000) and by trawl operation (outside, summer 2001) indicated the presence of the same dominant species: Sardina pilchardus, Engraulis encrasicholus, Boops boops and Trachurus trachurus.

\subsection{Individual fish (Target Strength)}

As expected, the overview of the echograms showed the usual pattern of fish in schools during the day and scattered during the night (Freon et al., 1996). Comparison of all the TS values by non-parametric tests (Kruskal-Wallis) showed no differences $(P<0.05)$ amongst the four TS distributions Fig. 6. Nevertheless, the TS distributions indicate the presence of a higher percentage of small fishes inside the MG than outside (Fig. 6), yet the maximum TS values were collected inside the MG. On average, the TS values were higher outside the MG. During the "lamparo" experiments, there was a shift towards large targets compared with the night TS values inside the MG Fig. 6. However, on average, there is no real change.

\subsection{Mussel longline structure}

Our results show that, using MBS, technology it was possible to:

- locate and count (GPS, vertical position) the mussel longlines in each concession;

- evaluate the mussel charge by segment $(50 \mathrm{~m})$ into the three categories described above and acoustically docu-

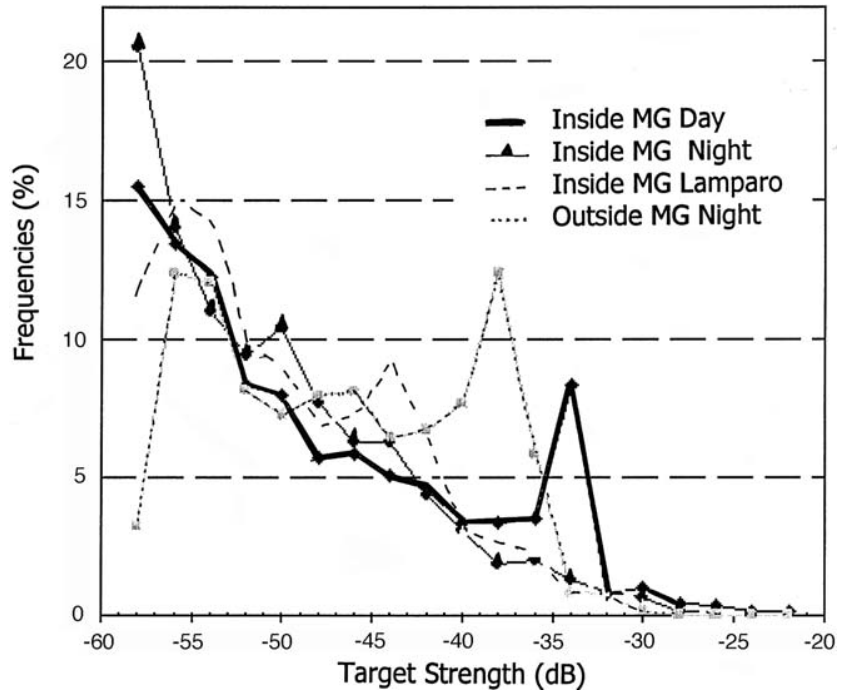

Fig. 6. Comparison of TS (in $\mathrm{dB}$ ) obtained outside and inside the mussel culture ground $(\mathrm{MG})$, at a same depth $(20-30 \mathrm{~m})$ : during the day, and during the night, with and without the "lamparo" light attraction experiment.

ment directly the disappearance of mussel ropes due to predation;

- observe the vertical behaviour of mussel rope in the water column Figs. 3 and 4 ;

- note the existence of lost or clandestine longlines, and record the bottom relief;

- document and monitor the interaction of fish and fish schools in the MG.

Digital MBS data processing via Sbiviewer software (Gerlotto et al., 1999) and MBS video recordings also allow reconstructing the longlines in three dimensions and the characterization of the longlines Fig. 4. It takes less than $10 \mathrm{~min}$ to record a longline exhaustively. Consequently, the total area of 2754 ha with 242 mussel longlines distributed on 171 concessions can be fully recorded in 1 week.

The behavioural ecology of schools relative to the longline was explored (e.g. attraction effect as described above). Fig. 4 shows the three-dimensional reconstruction of a school close to the part of the longline where the mussel charge is the most abundant. This kind of three-dimensional imagery allows an accurate evaluation of the influence of the longline features on school distribution and behaviour. LOS observations were undertaken with a Simrad SR240 (filter: Reverberation Control Gain/strong, Ping to Ping/strong, Auto Gain Control/off) on the MG (Table 1). The data show that the fixed longline can be discriminated from the mobile biological target. This provides information on the time of residence of fish schools and their horizontal swimming behaviour around the mussel longline structure.

\section{Discussion}

The objective of this project was to discriminate fish schools from non-biological targets. The objective has been successful. Our results confirmed that the combined use of 
VES and MBS digital and analogical video data allows an accurate discrimination of the fish echoes, individuals as well as in schools, from the non-biological target in a complex environment (mussel longline structure). These results have to be supplemented by systematic species recognition using fishing, underwater observation or acoustic identification (multifrequencies, school shape, etc.). However, shoal measurement (Pitcher, 1983) and the definition of mussel charge require specific tests (i.e., standardization by direct in situ observation).

Detection of predators was not achieved.

Simultaneous use of multibeam sonar and classical echo sounder allowed discriminating artefact echoes from schools. For this work, we used a MOVIES+ function (Weill et al., 1993; Berger et al., 2001) to zoom on each "false echo" and delete them before a complete process of VES (echo integration, TS measurement, fish school discrimination). A similar procedure could be used to discriminate trees and fish in non-deforested dams (Cardenas et al., 1988).

The local managers have planed to restructure the area. The MBS can provide useful information on the under water structures and 3D topography for such purposes. Our methodology allows recording all the mussel longlines and detection of clandestine or lost longlines, even those unseen from the surface. An exhaustive mapping of the MG production is made possible. It is possible to locate, count, observe the state of the mussel longlines in the MG, and to deliver data for a global management of the area. All these data are complementary and are of great interest to the local administrative managers and fisheries or aquaculture scientists.

The information provided by our study can help in evaluating the catchability coefficient of fish and schools by different fishing techniques. Fishing with light appears to be efficient on certain targets, and samples inside the channel may not provide any useful information (weak abundance) (Brehmer, 2001).

The TS values indicate the presence of big fish, suspected to be Sparids as described by the professionals (Moran, pers. comm.), inside the MG in night time. Small fish are four times more abundant inside the MG than outside Fig. 6. This could be due to the refuge effect of the structures (reduced current and area prohibited to navigation), with the presence of higher taxonomic composition (fauna and flora) of the suspended mussel rope unit due to their interaction with the environment (Mazouni et al., 2001; Deslous-Paoli et al., 1998). The mussel aquaculture can play a central role in nitrogen renewal in the water column (Mazouni et al., 1998) and shellfish farming nutrient transformation increases ecosystem productivity even if the filtration pressure keeps phytoplankton biomass at low level (Deslous-Paoli et al., 1998). A concept of "mussel rope forest" is defended in the book of Lacroix et al. (2002), for increasing the potential of artificial reef attraction. Fig. 5 shows the opposite for schools inside and outside the MG. Conversely, the TS data show no significant differences in the distribution inside/outside; the predominant species are the same. Since the species are the same, the school morphological variation must be related to different behavioural motivations inside and outside the MG.

We were unable to draw any conclusion on the effect of such structures as artificial reefs (fish biomass attraction and/or production) but we pointed out the differences in fish behaviour inside and outside the MG. Attraction seems evident, if measured in terms of biodiversity, but the mechanisms have not been quantified or identified. The sampling survey design must be adapted to investigate the potential attraction of such "artificial reefs". The comparison of fish school spatial structure with a spatial point process approach (Petitgas et al., 1996) and biomass assessment could be a good indicator of the "reef effect" on the fish resources coupled with species richness study (Bayley and Peterson, 2001). Productivity needs a multiyear study (fish assessment, evaluation of biomass and diversity on the mussel longline fauna and flora) with at least, bi-annual surveys to take into consideration the species seasonality (water temperature variations). The methodology we developed provides information for a rational management of the coastline, such as inventory of mussel culture, effect of artificial reefs, and fish behaviour. A regularly use of this methodology will insure an evaluation of the evolution of pelagic fish population around the MG according to the MG activities. A comparative approach at annual or seasonal scale (temperature and salinity variation observed seasonal change of the taxonomic richness of biofouling (Souchu et al., 1997; Mazouni et al., 2001)) should provide information for fisheries scientist and local manager. The methodology can be applied on natural or artificial reef as plane sand bottom under Fish Aggregation Devices (Hunter and Mitchel, 1967).

An optimized methodology could be added with information obtained by LOS, to use MBS with ping sector of $180^{\circ}$ (Gerlotto et al., 1999; Mayer et al., 2002), Radio-Acoustic Positioning and Telemetry (O'Dor et al., 2000) and Ultrasonic Telemetry (Bolden, 2000) for an exhaustive view of fish behaviour.

\section{Conclusion}

The integration of observations into three dimensions allows several exploratory options and an overview of the fish behaviour. Fish structure, fish aggregation dynamics, swimming behaviour, time of residence, catchability, spatial occupancy, diel variations, interaction with the mussel rope, etc. and a complete fish school database can be built with the three devices VES, MBS and LOS (Brehmer et al., 2002). Automation of digital sonar data acquisition and analysis software would provide more reliable information on school characteristics.

The aim of our work, to observe fish in a shallow water ecosystem, was successfully achieved. However, an important unexpected result was the demonstration of the capacity of modern acoustic systems to monitor such areas, at several levels. The results of this study clearly demonstrate that the MBS technology can be used for the discrimination between 
the non-biological targets like the mussel longline and biological echoes such as shoals and fish schools. In addition, the technology permits the evaluation of lost and/or clandestine gears, evaluation of the global impact of aquaculture structures on the whole ecosystem, as well as changes and shifts in the trophic levels of the area. Although some technical and methodological improvements have to be designed, a wide field of activities is open to underwater acoustics, and the methods may be available to managers to monitor their activities in detail. If the management of human activities and exploitation must be considered in an ecosystem-based approach, being able to describe in detail and in a qualitative as well as quantitative way, the whole system becomes critical. Acoustic methods, such as the one we presented in this paper, seem to be able to provide this kind of information on the different parameters of the ecosystem. It seems clear that an integrated approach of the mussel culture ground, gathering in a synoptic data base: the artificial structure, the aquaculture status of the mussels and the fish behaviour and abundance, will be of great help to evaluate the potential of an area, and the ecological health of an anthropized ecosystem.

\section{Acknowledgements}

To the Languedoc Roussillon region which supports this program by the measure 13.4.4, 03-04/01; CPER 2000-2006. To the Mediterranean aquaculture farmers of SRCM-ASA for their participation. We are also grateful to the anonymous reviewers who contributed to improve the text. The research facilities were provided by the new centre of Mediterranean and tropical fisheries research (CRHMT: IRD, Ifremer and University of Montpellier II).

\section{References}

Bayley, P.B., Peterson, J.T., 2001. An approach to estimate probability of presence and richness of fish. Trans. Am. Fish. Soc. 130, 620-633.

Berger, L., Durand, C., Marchalot, C., 2001. Movies+ User Manual version 3.3. Ifremer, Brest.

Bolden, S.K., 2000. Using ultrasonic telemetry to determine home range of a coral-reef fish. In: Sibert, J.R., Nielsen, J.F. (Eds.), Electronic Tagging and Tracking in Marine Fisheries. Kluwer Academic Publishers, London, pp. 167-179.

Brehmer, P., Gerlotto, F., 2000. Methodology concept and preliminary analysis on omnidirectional sonar data. In: Zakharia, M.E., Chevret, P., Dubail, P. (Eds.), Proceedings of the Fifth European Conference on Underwater Acoustics. Commission Européenne, Luxembourg, pp. $1527-1532$.

Brehmer, P., 2001. Observations acoustiques de bancs de poissons autour de filières à moules en mer ouverte à l'aide d'un sonar multi-faisceaux à haute résolution $(455 \mathrm{kHz})$ : application au lotissement conchylicole de Sète-Marseillan. Doc Sci. IRD-Region LR 13.4.4 Montpellier, France.
Brehmer, P., Gerlotto, F., Rouault, A., 2002. In situ inter-standardization of acoustic data: an integrated database for fish school behaviour studies. Acta Acoust. 88, 730-734.

Cardenas, L., Petit, J.J., Nova, D., 1988. Hydroacoustic surveys of Guri lake (Venezuela) a preliminary assay on the quantification and distribution of fish biomass. Mem. Cien. Nat. La Salle 47, 77-90.

Deslous-Paoli, J.M., Souchu, P., Mazouni, N., Juge, C., Dagault, F., Chardy, P., 1998. Relationship between environment and resources: impact of shellfish farming on a Mediterranean lagoon (Thau, France). Oceanol. Acta 21, 831-843.

Freon, F., Gerlotto, F., Soria, M., 1996. Diurnal variation of school structure with special reference to transition periods. ICES J. Mar. Sci. 53, 459464.

Foote, K.G., 1987. Calibration of acoustic instruments for fish density estimation: a practical guide. ICES Coop. Res. Rep. No. 144.

Gerlotto, F., Soria, M., Fréon, P., 1999. From two dimensions to three: the use of multibeam sonar for a new approach in fisheries acoustics. Can. J. Fish. Aquat. Sci. 56, 6-12.

Gerlotto, F., Brehmer, P., Buestel, D., Sanguinede, F., 2001. A method for acoustics monitoring of a mussel longline ground using vertical echosounder and multibeam sonar. ICES CM/R:01.

Hunter, J.R., Mitchel, C.T., 1967. Association of fishes with floatam in the offshore waters of central America. Fish. Bull. 66, 13-29.

Lacroix, D., Dao, J.-C., Veron, G., Buestel, D., Mellon, C., Lagardere, J.P., Coves, D., Charbonnel, E., 2002. Les récifs artificiels : aménagement du littoral et repeuplement. In: Lacroix, D. (Ed.), Bilans et perspectives, Ifremer.

Loste, C., Cazin, F., 1993. La conchyliculture en mer ouverte en Languedoc Roussillon, situation en 1992. Région Languedoc Roussillon CEPRALMAR Montpellier.

Mayer, L., Li, Y., Melvin, G., 2002. 3D visualization for pelagic fisheries research and assessment. ICES J. Mar. Sci. 59, 216-225.

Mazouni, N., Gaertner, J.-C., Deslous-Paoli, J.-M., 2001. Composition of biofouling communities on suspended oyster cultures: an in situ study of their interactions with the water column. Mar. Ecol. Prog. Ser. 214, 93-102.

Mazouni, N., Deslous-Paoli, J.-M., Landrein, S., 1998. Impact of oyster culture on nutrients and oxygen fluxes in a coastal lagoon. Oceanol. Acta $21,845-858$.

Nédélec, C., Prado, J., 1990. Definition and classification of fishing gear categories. FAO Fish. Tech. Pap. 222.

O'Dor, R.K., Aitken, J.P., Babcock, R.C., Bolden, S.K., Seino, S., Zeller, D.C., Jackson, G.D., 2000. Using radio-acoustic positioning and telemetry (RAPT) to define and assess marine protected areas (MPAs). In: Sibert, J.R., Nielsen, J.F. (Eds.), Electronic Tagging and Tracking in Marine Fisheries. Kluwer Academic Publishers, London, pp. 147-158.

Petitgas, P., Monimeau, L., Brehmer, P., Gerlotto, F., 1996. Characterising the spatial distribution of fish schools with a point process approach: a first application on sonar recordings. ICES CM96/B:31.

Pitcher, T.J., 1983. Heuristic definitions of shoaling behaviour. Anim. Behav. $31,611-613$.

Souchu, P., Gasc, A., Cahet, G., Vaquer, A., Collos, Y., Deslous-Paoli, J.-M., 1997. Biogeochemical composition of Mediterranean waters outside Thau Lagoon. Estuar. Coast. Shelf. Sci. 44, 275-284.

Weill, A.C., Scalabrin, C., Diner, N., 1993. MOVIES-B: an acoustic detection description software. Application to shoal species classification. Aquat. Living Resour. 6, 255-267. 